\title{
Identification of hypoxanthine as a urine marker for non-Hodgkin lymphoma by low-mass-ion profiling
}

Byong Chul Yoo ${ }^{1}$, Sun-Young Kong ${ }^{2}$, Sang-Geun Jang ${ }^{1}$, Kyung-Hee Kim ${ }^{1}$, Sun-A Ahn', Weon-Seo Park², Sohee Park ${ }^{3}$, Tak Yun ${ }^{4}$, Hyeon-Seok Eom ${ }^{2,4^{*}}$

\begin{abstract}
Background: Non-Hodgkin lymphoma (NHL) is a hematologic malignancy for which good diagnostic markers are lacking. Despite continued improvement in our understanding of NHL, efforts to identify diagnostic markers have yielded dismal results. Here, we translated low-mass-ion information in urine samples from patients with NHL into a diagnostic marker.
\end{abstract}

Methods: To minimize experimental error, we tested variable parameters before MALDI-TOF analysis of low-mass ions in urine. Urine from 30 controls and $30 \mathrm{NHL}$ patients was analyzed as a training set for NHL prediction. All individual peak areas were normalized to total area up to $1000 \mathrm{~m} / \mathrm{z}$. The training set analysis was repeated four times. Low-mass peaks that were not affected by changes in experimental conditions were collected using MarkerView ${ }^{\mathrm{TM}}$ software. Human Metabolome Database (HMDB) searches and ESI LC-MS/MS analyses were used to identify low-mass ions that exhibited differential patterns in control and NHL urines. Identified low-mass ions were validated in a blinded fashion in 95 controls and $66 \mathrm{NHL}$ urines to determine their ability to discriminate $\mathrm{NHL}$ patients from controls.

Results: The 30 highest-ranking low-mass-ion peaks were selected from the 60-urine training set, and three lowmass-ion peaks with high intensity were selected for identification. Of these, a 137.08-m/z ion showed lower masspeak intensity in urines of NHL patients, a result that was validated in a 161-urine blind validation set (95 controls and $66 \mathrm{NHL}$ urines). The $130.08-\mathrm{m} / \mathrm{z}$ ion was identified from HMDB searches and ESI LC-MS/MS analyses as hypoxanthine $(H X)$. The HX concentration in urines of NHL patients was significantly decreased $(P<0.001)$ and was correlated with the mass-peak area of the $137.08-\mathrm{m} / \mathrm{z}$ ion. At an $\mathrm{HX}$ concentration cutoff of $17.4 \mu \mathrm{M}$, sensitivity and specificity were $79.2 \%$ and $78.4 \%$, respectively.

Conclusions: The present study represents a good example of low-mass-ion profiling in the setting of disease screening using urine. This technique can be a powerful non-invasive diagnostic tool with high sensitivity and specificity for $\mathrm{NHL}$ screening. Furthermore, $\mathrm{HX}$ identified in the study may be a useful single urine marker for $\mathrm{NHL}$ screening.

\section{Backgrounds}

Non-Hodgkin lymphomas (NHL) are a heterogeneous group of malignancies that arise from lymphoid tissue. They exhibit varied clinical and biological features [1], and their incidence has been increasing over the past several decades [2]. The past decade has seen enormous

\footnotetext{
* Correspondence: hseoum@ncc.re.kr

${ }^{2}$ Hematologic Malignancies Branch, Division of Translational and Clinical Research II, Goyang-si, Republic of Korea
}

changes in our understanding of lymphomas, including the identification of better prognostic factors [3]. However, results from efforts to identify good diagnostic factors have been disappointing. Lactate dehydrogenase has been used as an NHL marker [4], but its accuracy in diagnosis has been unsatisfactory. Thus, finding specific tumor markers that are useful for diagnosing and monitoring NHL remains a high priority. In the present study, we introduce a new NHL diagnostic marker 
obtained by translating the information in low-mass ions (i.e., $<1000 \mathrm{~m} / \mathrm{z}$ ) in urine samples from lymphoma patients.

\section{Methods}

Urine from patients with $\mathrm{NHL}$

Urine samples were obtained from 125 healthy controls (65 males and 60 females, median age 50.0 years old) and 96 patients with NHL (61 males and 35 females, median age 57.0 years old). All samples were stored at $4^{\circ} \mathrm{C}$ before processing and were processed within 6 hours of collection. Processed samples were frozen at $-80^{\circ} \mathrm{C}$ until assessment. The characteristics of NHL patients are listed in Table 1 . Informed consent was obtained from all patients, and the research protocol was approved by the Institutional Review Board of the National Cancer Center, Korea (NCCCTS-05-146).

\section{MALDI-TOF analytical conditions for collecting low-mass} ions in urine

Urine samples were mixed (1:12) with an $\alpha$-cyano-4hydroxycinnamic acid solution in $50 \%$ acetonitrile/ $0.1 \%$ trifluoroacetic acid (TFA). Differences between normal and cancer urine samples were determined using a 4700 Proteomic Analyzer (Applied Biosystems, Foster City, CA, USA). The mass-spectral data represent the average of 20 accumulated spectra.

\section{Low-mass ion selection and statistical analysis}

All MALDI mass spectra, formatted as *.t2d files, were analyzed with MarkerView ${ }^{\mathrm{TM}}$ Software version 1.2 (Applied Biosystems/MDS Sciex, Toronto, Canada). The optimized parameters used to compare low-mass peaks in urines from controls and NHL patients were as follow: Mass tolerance, $100 \mathrm{ppm}$; minimum required response, 100; maximum number of peaks, 5000; normalization, by total area sums. After collecting information from MALDI mass spectra, principal component analyses (PCA) and t-tests were used to select low-mass ions with differential peak intensities in urines from controls and NHL patients.

\section{ESI-MS/MS for low-mass ion analysis}

MALDI-TOF was not suitable for comparing MS/MS patterns of low-mass ions, so ESI-MS/MS was employed. The mass spectrometer was set for ESI in positive mode. A syringe pump was used to introduce the calibration solution for automatic tuning and calibration of the LTQ-XL (Thermo Fisher Scientific Inc., Waltham, MA) in ESI positive-ion mode. Standard solutions ( $1 \mu \mathrm{M}$ hypoxanthine) were infused directly into the ionization source of the mass spectrometer using a syringe pump $(1.0 \mu \mathrm{L} / \mathrm{min})$ without chromatographic separation. The spray voltage was set at $+1.1 \mathrm{kV}$; the
Table 1 The characteristics of 96 NHL patients

\begin{tabular}{|c|c|}
\hline & No. of Patients (\%) \\
\hline Age, years (median, range) & $57,23-87$ \\
\hline \multicolumn{2}{|l|}{ Sex } \\
\hline Male & $61(63.5)$ \\
\hline Female & $35(36.5)$ \\
\hline \multicolumn{2}{|l|}{ Histologic type (WHO) } \\
\hline Diffuse large B cell lymphoma & $70(72.9)$ \\
\hline Mantle cell lymphoma & $6(6.2)$ \\
\hline$T$ cell lineage & $16(16.7)$ \\
\hline Follicular lymphoma & $2(2.1)$ \\
\hline Burkitt's lymphoma & $2(2.1)$ \\
\hline \multicolumn{2}{|l|}{ Performance status } \\
\hline 0 & $32(33.3)$ \\
\hline 1 & $60(62.5)$ \\
\hline 2 & $4(4.2)$ \\
\hline \multicolumn{2}{|l|}{ Stage } \\
\hline I & $16(16.7)$ \\
\hline$\|$ & $40(41.6)$ \\
\hline III & $18(18.8)$ \\
\hline IV & $22(22.9)$ \\
\hline \multicolumn{2}{|l|}{ Extra-nodal involvement } \\
\hline Absent & $43(44.8)$ \\
\hline Present & $57(55.2)$ \\
\hline \multicolumn{2}{|l|}{ IPI } \\
\hline Low & $52(54.1)$ \\
\hline Low-intermediate & $18(18.8)$ \\
\hline High-intermediate & $20(20.8)$ \\
\hline High & $6(6.3)$ \\
\hline \multicolumn{2}{|l|}{ Bone marrow involvement } \\
\hline Absent & $90(93.8)$ \\
\hline Present & $5(5.2)$ \\
\hline Not identified & $1(1.0)$ \\
\hline \multicolumn{2}{|l|}{ Therapeutic regimen } \\
\hline $\mathrm{R}-\mathrm{CHOP}$ & $79(82.3)$ \\
\hline $\mathrm{CHOP}$ & $8(8.3)$ \\
\hline Others & $9(9.4)$ \\
\hline
\end{tabular}

In histologic type, T cell lineage includes anaplastic large cell lymphoma, angioimmunoblastic T cell lymphoma, peripheral T cell lymphoma, and NK/T cell lymphoma. Except of follicular lymphoma as an indolent type of NHL, all other histologic subclasses represent aggressive type.

Performance status was determined according to the criteria, ECOG score. IPI: international prognostic index

CHOP regimen includes cyclophosphamide, doxorubicin, vincristine, and prednisolone. $\mathrm{R}-\mathrm{CHOP}$ is a combination regimen of $\mathrm{CHOP}$ with the anti-CD20 monoclonal antibody, rituximab.

temperature of the capillary was set at $200^{\circ} \mathrm{C}$; the capillary voltage was set at $+20 \mathrm{~V}$; the tube lens voltage was set at $+100 \mathrm{~V}$; and the auxiliary gas was set to zero. Full-scan experiments were performed to linear trap in the range, $100-200 \mathrm{~m} / \mathrm{z}$. Systematic MS/MS experiments were performed by changing the relative collisional energy and monitoring the intensities of the fragment ions. MS/MS data were acquired from urine samples. 
Dtermination of hypoxanthine and xanthine in urines

The concentration of hypoxanthine and xanthine in urines was determined using the Amplex ${ }^{\odot}$ Red Xanthine/ Xanthine Oxidase Assay Kit (Molecular Probes, Inc., Eugene, OR), according to the manufacturer's instructions.

\section{Results}

Experimental conditions for MALDI MS analysis of lowmass ions in urine

To minimize experimental error, we tested variable parameters, including focus mass, laser intensity, target plate and data-acquisition time. Ideal focus mass and laser intensity for analyzing low-mass ions $(<\sim 1000 \mathrm{~m} / \mathrm{z})$ were fixed at $500 \mathrm{~m} / \mathrm{z}$ and 5250, respectively (Figure 1A, B and $1 C)$. Using these focus mass and laser intensity settings, we analyzed one urine sample four times under different target and data acquisition times. Low-mass peaks that were not significantly affected by experimental conditions were selected and subsequently evaluated for their potential ability to discriminate NHL from normal controls (Figure 1D).

\section{Selection of low-mass ions differentially present in control and NHL urines}

Using MarkerView ${ }^{\mathrm{TM}}$ statistical software, we compared the patterns of low-mass ion spectra in urines of 30 normal and 30 NHL patients. Contamination by the chemical matrix used in MALDI-TOF analysis was ruled out based on a statistical analysis (data not shown). A principal component analysis (PCA) showed differential peak patterns of low-mass ions in control and NHL urines (Figure 2A). Among the low-mass ions ranked in the top 30 by PCA (Figure 2B), three with the highest peak intensity were selected for further analysis. The peak intensity of the $137.08-\mathrm{m} / \mathrm{z}$ ion was much lower in urines from NHL patients than in normal urines $(\mathrm{P}<0.001)$ (Figure $2 \mathrm{~B}$ $\& 2 \mathrm{C}$ ), whereas those of the other two selected low-mass ions $(172.07$ and $182.07 \mathrm{~m} / \mathrm{z})$ were higher in urines from NHL patients (both $\mathrm{P}<0.001$ ) (Figure $2 \mathrm{~B}$ ). A profile plot of $137.08-\mathrm{m} / \mathrm{z}$ peaks suggested that this ion has discriminating power for NHL screening (Figure 2C).

\section{Identifications for the $137.1 \mathrm{~m} / \mathrm{z}$ ion in urine as hypoxanthine}

Candidate metabolites corresponding to the $137.08-\mathrm{m} / \mathrm{z}$ ion were searched using the Human Metabolome Database (HMDB). Many metabolites with a mass tolerance of $137.08 \pm 0.05(137.08 \mathrm{~m} / \mathrm{z}$ was rounded off to three decimal places) were searched in positive mode. Among these, only eight appeared as an $\mathrm{M}+\mathrm{H}$ adduct (Table 2). Because it is a representative metabolite in urine metabolic pathways, Hypoxanthine was tested first to determine whether it corresponded to the $137.08 \mathrm{~m} / \mathrm{z}$ mass peak in urine. To assure the best possible MS/MS analysis of low-mass ions, we employed ESI LC-MS/MS (LTQ-XL, Thermo Fisher Scientific Inc., Waltham, MA), monitoring the mass-shift of hypoxanthine and the $137.08-\mathrm{m} / \mathrm{z}$ ion in urine at $137.70 \mathrm{~m} / \mathrm{z}$ (Figure 3A). Interestingly, the MS/MS pattern of both low-mass ions was identical (Figure 3B). In contrast, the MS/MS patterns of other candidate metabolites, such as N-methylnicotinamide (Table 2), differed from that of the $137.1-\mathrm{m} / \mathrm{z}$ ion in urine (data not shown), and were thus ruled out.

The mass-peak area of the 137.08- $\mathrm{m} / \mathrm{z}$ ion and hypoxanthine were correlated with one another (Figure 3C), but this relationship did not reach statistical significance. Mass accuracy (Figure 3A \&3B) and the relationship between mass-peak area of the $137.08-\mathrm{m} / \mathrm{z}$ ion and hypoxanthine concentration (Figure $3 \mathrm{C}$ ) suggested that differential levels of HX in control and NHL urines resulted in a change in the mass-peak area of the $137.08-\mathrm{m} / \mathrm{z}$ ion. Despite this unsatisfied statistical relationship, hypoxanthine was significantly reduced in NHL urines $(\mathrm{P}<0.001)$; at a $17.4-\mu \mathrm{M}$ cutoff, specificity and sensitivity were $78.4 \%$ and $79.2 \%$, respectively (Figure 4A). Furthermore, xanthine produced from hypoxanthine by xanthine oxidase was also lower in NHL urines, and showed a similar NHL-discriminating power (76.0\% specificity and 78.1\% sensitivity; Figure 4B).

\section{Clinicopathological relevance of NHL discriminating low- mass ions in urine}

Neither of the two NHL-discriminating low-mass ions, hypoxanthine and xanthine, was significantly correlated with individual histologic types, cancer stage, extranodal involvement, Eastern Cooperative Oncology Group score (ECOG performance), international prognostic index (low, low/intermediate vs. high/intermediate, high), bone marrow involvement (absent vs. present), first response to chemotherapy (complete response, partial response vs. stable disease, progressive disease) or survival (data not shown).

\section{Discussion}

Previous efforts to find diagnostic factors for NHL have yielded disappointing results compared with studies reporting prognostic factors with clinicopathological correlations $[5,6]$. Our previous study showed that the urine level of IL- 8 normalized to creatinine could be a possible biomarker with the capacity to discriminate NHL patients from normal controls; thus, we expected that urine might be a valuable biological source for diagnostic markers for NHL [7].

In the present study, we sought to develop a new diagnostic approach for NHL, using MALDI-MS analysis to translate the information of low-mass ions (i.e., < $\sim 1000 \mathrm{~m} / \mathrm{z}$ ) present in urine samples into a tool capable of discriminating NHL patients from normal individuals. 
A

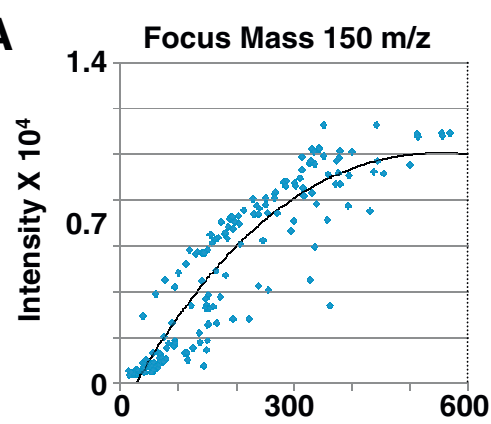

Focus Mass 300 m/z

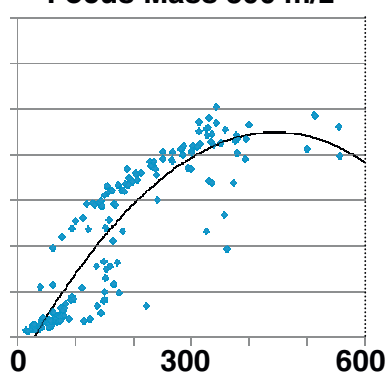

Focus Mass $500 \mathrm{~m} / \mathrm{z}$

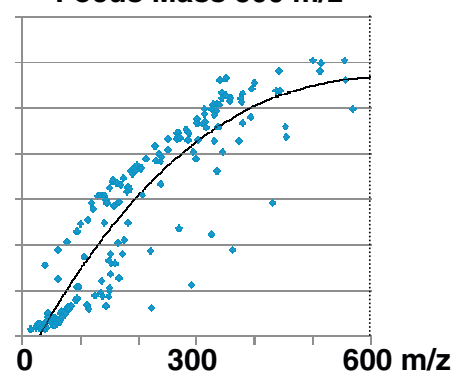

B 100

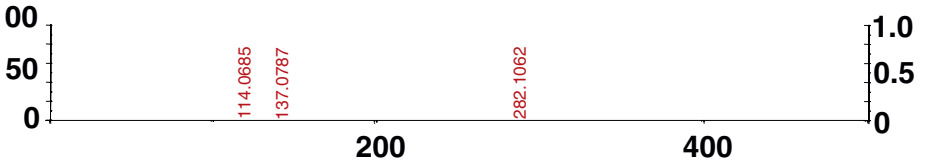

Laser intensity : 4500

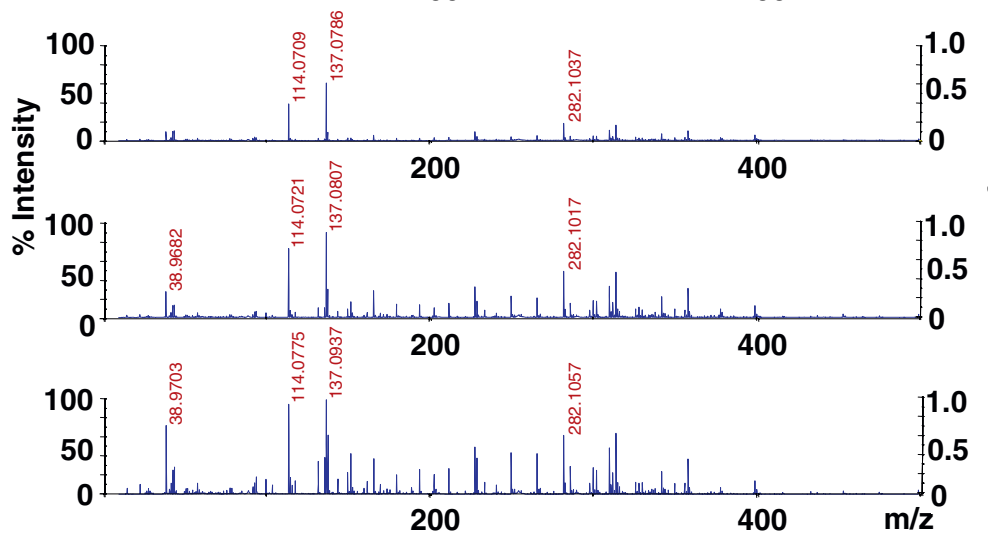

Laser intensity : $\mathbf{5 3 0 0}$

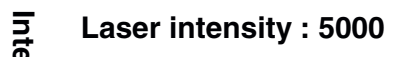

Laser intensity : 5500
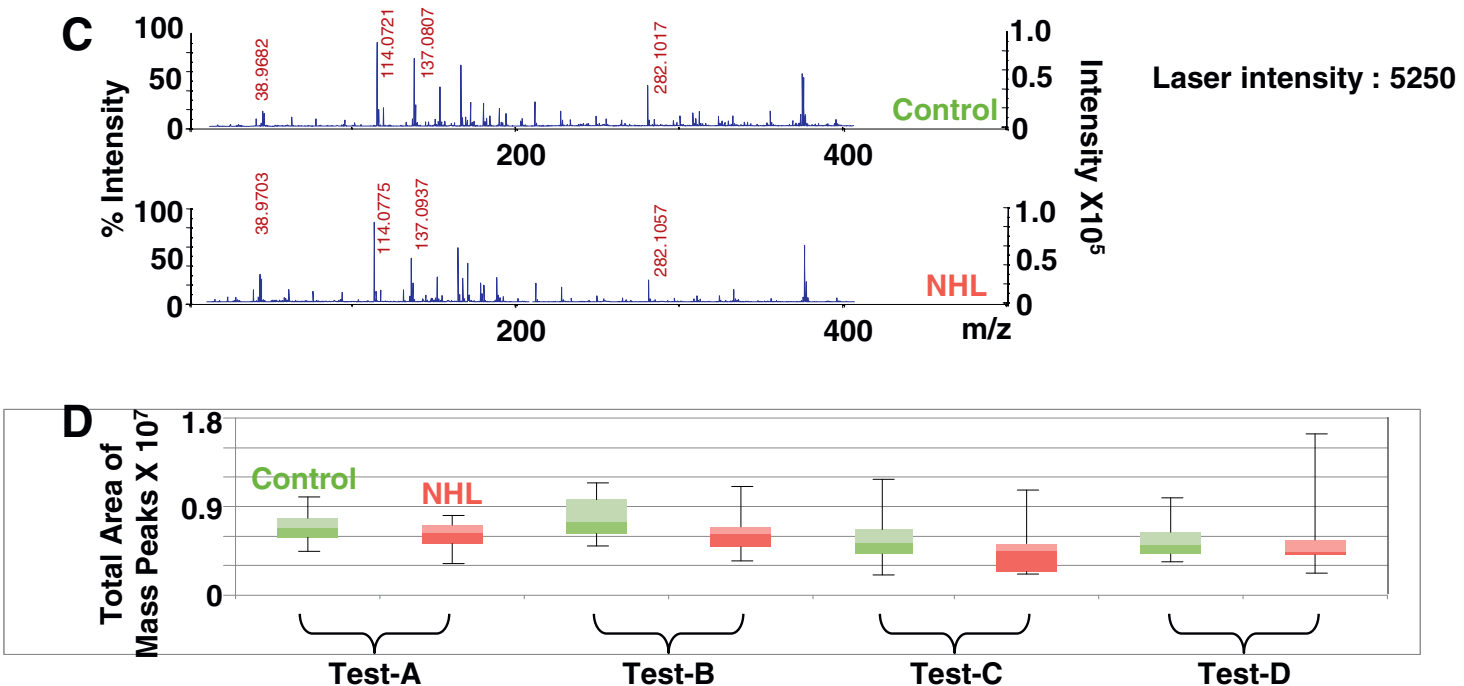

Figure 1 Selection of two low-mass ions with differential peak areas in urines from controls and NHL patients after establishing MALDI-MS conditions for low-mass-ion profiling. A. The resolution of mass peaks acquired at variable focus mass. Linear resolution of lowmass peaks was obtained at a focus mass of $500 \mathrm{~m} / \mathrm{z}$. B. The effect of laser intensity on overall mass spectrum acquisition. Laser intensity was positively correlated with the area of low-mass peaks $(<1000 \mathrm{~m} / \mathrm{z})$. Because low-mass peaks with the highest intensity become saturated at a laser intensity of 5500, the laser intensity for data acquisition was fixed at 5250. C. Typical pattern of mass spectra from urines from controls and NHL patients. D. Box plot of total area of low-mass peaks $(<1000 \mathrm{~m} / \mathrm{z})$. The total area of low-mass peaks was obtained from four replicate experiments (cases A to D) using urines from 12 controls (green) and $11 \mathrm{NHL}$ patients (pink). 
Table 2 Metabolites with $137.07 \pm 0.05 \mathrm{~m} / \mathrm{z}$ in a positive-mode mass detection

\begin{tabular}{|c|c|c|c|c|c|}
\hline HMDB ID & Common Name & $\begin{array}{l}\text { Chemical } \\
\text { Formula }\end{array}$ & $\begin{array}{c}\text { Adduct MW (Da) } \\
\text { [Matching HMDB MW] }\end{array}$ & $\begin{array}{c}\text { MW Difference (Da) } \\
\text { [QueryMass - AdductMass] }\end{array}$ & Adduct \\
\hline HMDB03152 & N-Methylnicotinamide & $\mathrm{C} 7 \mathrm{H} 8 \mathrm{~N} 2 \mathrm{O}$ & $137.070938[136.063660]$ & 0.004333 & $\mathrm{M}+\mathrm{H}[1+]$ \\
\hline HMDB00209 & Benzeneacetic acid & $\mathrm{C} 8 \mathrm{H} 8 \mathrm{O} 2$ & 137.059708 [136.052429] & 0.006897 & $\mathrm{M}+\mathrm{H}[1+]$ \\
\hline HMDB01326 & Phenyl acetate & $\mathrm{C} 8 \mathrm{H} 8 \mathrm{O} 2$ & 137.059708 [136.052429] & 0.006897 & $\mathrm{M}+\mathrm{H}[1+]$ \\
\hline HMDB11659 & 2-Methylerythritol & $\mathrm{C} 5 \mathrm{H} 12 \mathrm{O} 4$ & 137.080841 [136.073563] & 0.014236 & $\mathrm{M}+\mathrm{H}[1+]$ \\
\hline HMDB01216 & Tetrahydropteridine & $\mathrm{C} 6 \mathrm{H} 8 \mathrm{~N} 4$ & 137.082184 [136.074905] & 0.015579 & $\mathrm{M}+\mathrm{H}[1+]$ \\
\hline HMDB00157 & Hypoxanthine & $\mathrm{C} 5 \mathrm{H} 4 \mathrm{~N} 4 \mathrm{O}$ & $137.045792[136.038513]$ & 0.020813 & $\mathrm{M}+\mathrm{H}[1+]$ \\
\hline HMDB00613 & Erythronic acid & $\mathrm{C} 4 \mathrm{H} 8 \mathrm{O} 5$ & 137.044449 [136.037170] & 0.022156 & $\mathrm{M}+\mathrm{H}[1+]$ \\
\hline HMDB00943 & Threonic acid & $\mathrm{C} 4 \mathrm{H} 8 \mathrm{O} 5$ & 137.044449 [136.037170] & 0.022156 & $\mathrm{M}+\mathrm{H}[1+]$ \\
\hline
\end{tabular}

$\mathrm{M}+\mathrm{H}[1+]$ adducts only are listed.

There are two motivations for our focus on this low-mass range. The first is the existence of valuable information in the low-mass range, analyzed by mass spectrometry, that has not yet been systematically exploited. Second, ions in the low-mass range provide an enormous amount of information about biological changes that originate from alterations in gene and protein expression. We hypothesized that a new non-invasive cancer-screening protocol could be established if low-mass-ion data were properly collected, statistically translated, and analyzed by MALDI-MS.

Interestingly, a low-mass ion appeared at $137.08 \mathrm{~m} / \mathrm{z}$ that was significantly different in urine samples from NHL patients and controls (Figure 2B \&2C). Searching the Human Metabolome Database (HMDB) yielded a list of candidate metabolites corresponding to the 137.08-m/z ion (Table 2). An ESI-MS/MS analysis of low-mass ions in urine identified $137.08 \mathrm{~m} / \mathrm{z}$ as hypoxanthine (Figure $3 \mathrm{~B}$ and $3 \mathrm{C}$ ). Consistent with this identification, the concentration of hypoxanthine in urine compared favorably with the MALDI-MS profile of the $137.08-\mathrm{m} / \mathrm{z}$ ion (Figure $3 \mathrm{C}$ ).

The Low-mass ion profiling is absolutely depends on the accurate mass measuring technology. Recent mass spectrometers employing either MALDI-, or ESI-based technology provide very accurate mass information. Using this advanced technology, we herein were able to suggest a possible application of low-mass ion profiling for cancer screening. However, a couple of problems are still remained. First, software for low-mass ion profiling is still incomplete. During the normalization process of mass spectra obtained from each individual samples, software sometimes collects the noise on the mass spectrum as a low-intensity peaks with discriminating power. To prevent this nose picking, low-mass ions ranked by software have to be checked again on the raw mass spectra. Furthermore, the low-mass ions with lowintensity, even they have a great discriminating power, may not be proper for identification. This is the reason why the low-mass ion with $137.08 \mathrm{~m} / \mathrm{z}$ was selected for identification since it showed highest intensity among the low-mass ions ranked within $30^{\text {th }}$ (Figure $2 \mathrm{~B}$ ).

In patients with gastric cancer or colorectal cancer, purine bases in plasma have been reported to increase in association with a decrease in purine base excretion [8]. Whether hypoxanthine and xanthine levels are altered in urine samples from gastrointestinal cancer patients is still a matter of debate [8]. In plasma from children with acute lymphoblastic leukemia or NHL, hypoxanthine levels were reported to be higher than those in healthy adult controls; these elevated plasma hypoxanthine levels decreased after methotrexate infusion [9]. However, a change in urine levels of hypoxanthine has not yet been reported.

At present, we are unable to explain the underlying mechanism for the change in hypoxanthine, but one possibility may be found in alterations of purine metabolism that occur during tumor development. Intracellular concentrations of hypoxanthine and xanthine are inversely related to adenylate energy changes and, therefore, to the energy currency of cellular ATP [10]. Recently, a classical antifolate has been shown to possess cytotoxic activity against human prostatic cancer cell lines that lacked hypoxanthine, whereas growth was maintained in tumors with hypoxanthine [11]. We reasoned that the level of hypoxanthine in NHL urines might decrease due to consumption by tumor cells. However, a recent study has shown that urinary hypoxanthine is significantly increased when tumor development in mesothelioma-transplanted nude mice was maximized [12]. In addition, changes in the activity or expression of enzymes involved in hypoxanthine or xanthine metabolism, which might affect hypoxanthine and xanthine levels in NHL urines, cannot be ruled out. For example, xanthine oxidoreductase, a key enzyme in the degradation of DNA and RNA, is associated with histological grade of differentiation and extent of disease in colorectal cancer [13], as well as the migratory activity of human breast cancer cells $[14,15]$. 

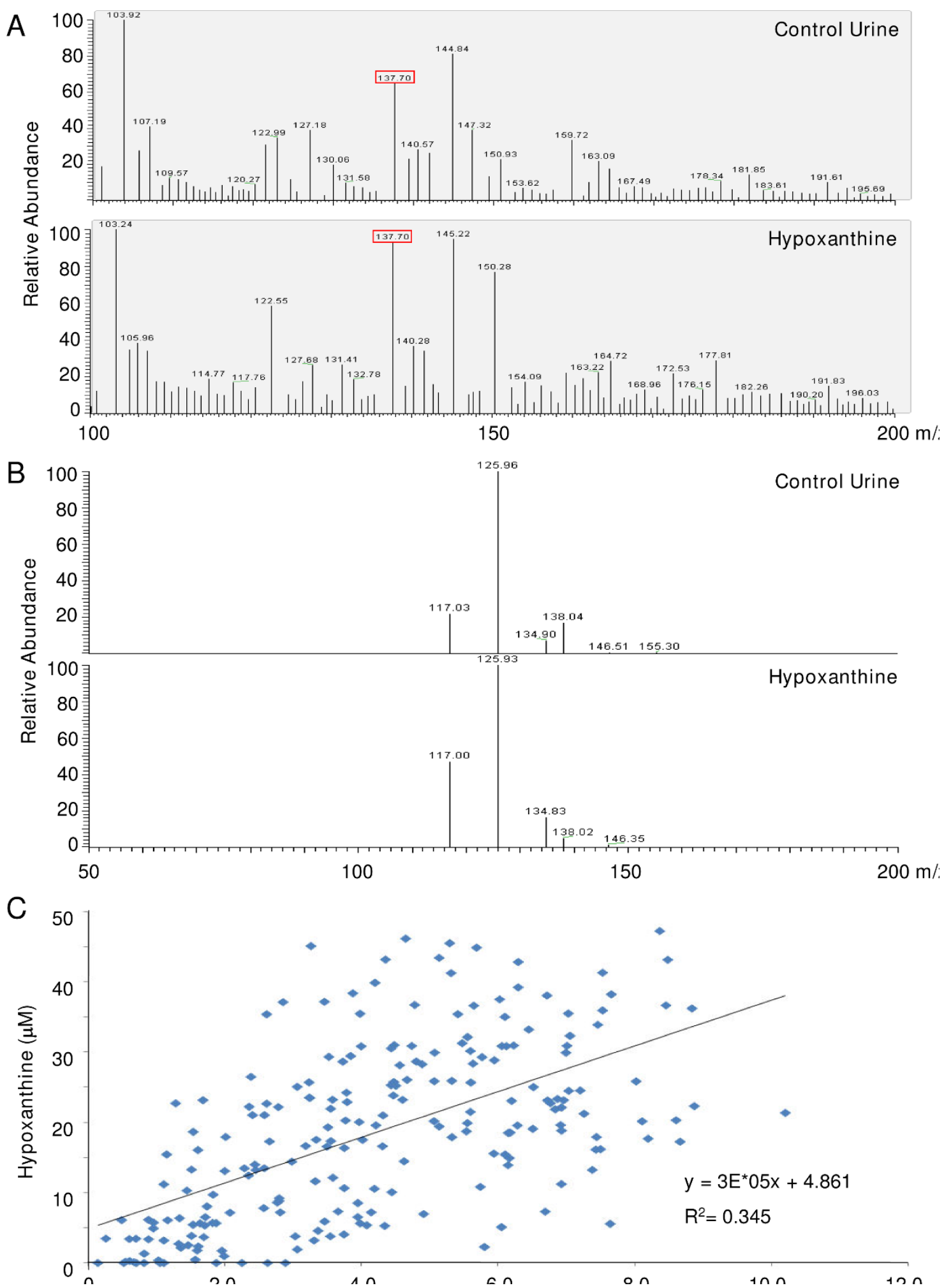

Figure 3 Identical ESI-MS/MS pattern obtained from $137.08 \mathrm{~m} / \mathbf{z}$ ion in urine and hypoxanthine. A. Mass shift of the $137.08-\mathrm{m} / \mathrm{z}$ ion in urine in LTQ-XL analysis. In a direct urine analysis without LC separation, the urine candidate $137.08-\mathrm{m} / \mathrm{z}$ ion and hypoxanthine $(H X)$ were monitored as $137.70 \mathrm{~m} / \mathrm{z}$. B. The ESI-MS/MS pattern of the 137.08-m/z ion in urine was identical to that of HX. C. Mass-peak area of the 137.08$\mathrm{m} / \mathrm{z}$ ion and HX concentration were positively correlated; however, this relationship did not reach statistical significance. 
A Hypoxanthine
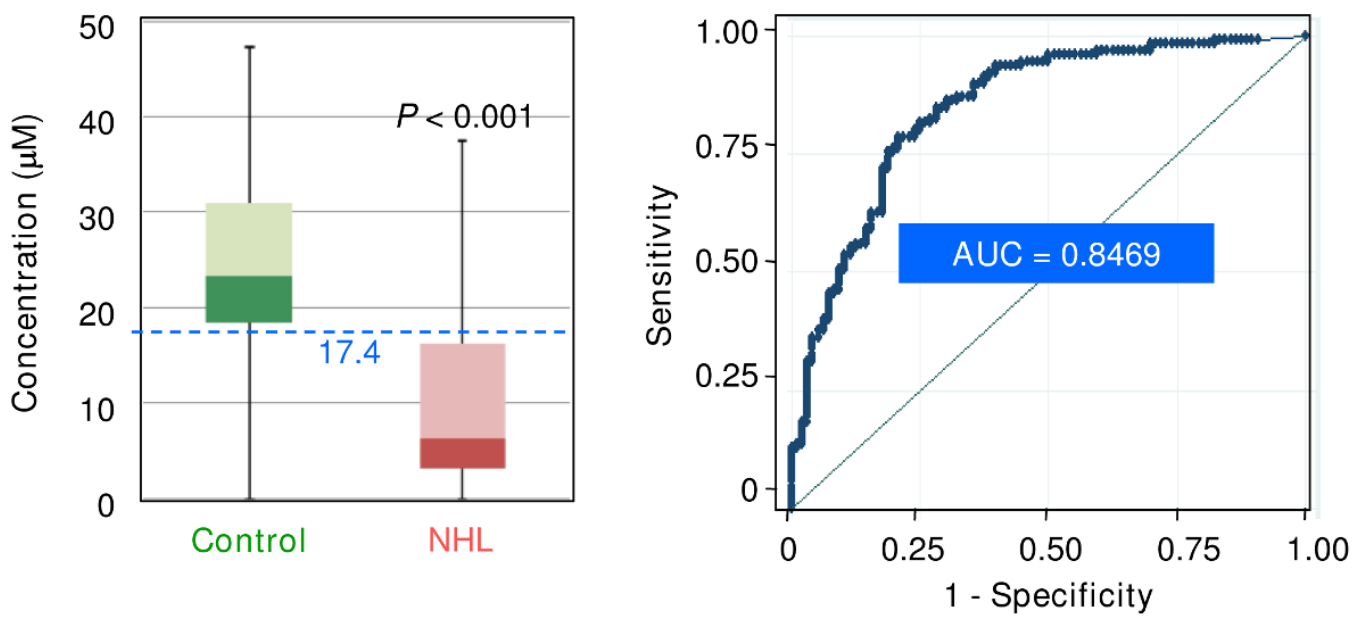

\begin{tabular}{ccc} 
& Predicted Control & Predicted NHL \\
\hline True Control & $98(78.4 \%)$ & $27(21.6 \%)$ \\
True NHL & $10(20.8 \%)$ & $76(79.2 \%)$
\end{tabular}

B
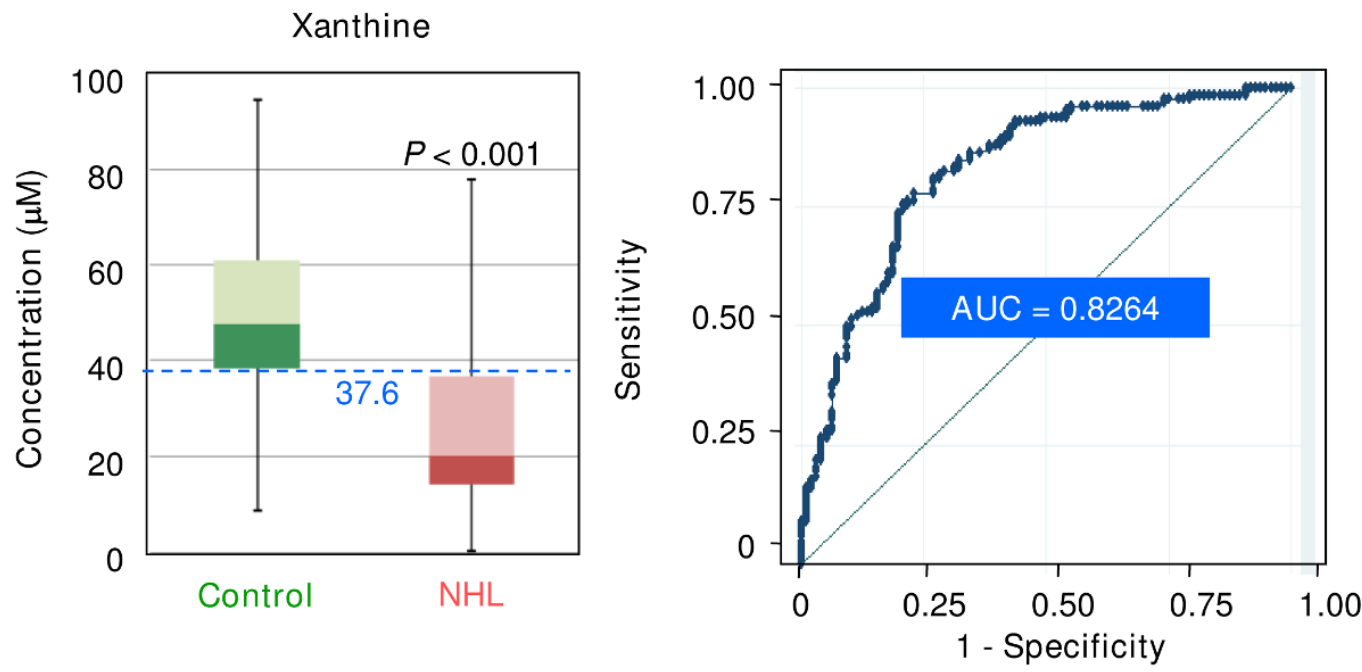

\begin{tabular}{ccc} 
& Predicted Control & Predicted $N H$ \\
\hline True Control & $95(76.0 \%)$ & $30(24.0 \%)$ \\
True NHL & $21(21.9 \%)$ & $75(78.1 \%)$
\end{tabular}

Figure 4 Significant decrease of hypoxanthine and xanthine in NHL urine. The levels of hypoxanthine (HX) (A) and its oxidative product, xanthine $(X)(B)$ were significantly lower in NHL urines (both $\mathrm{P}<0.001$ ). Area under the curve, sensitivity and specificity obtained from blind validation of 221 urines samples (125 control, and $96 \mathrm{NHL})$ are shown. 


\section{Conclusions}

The present study represents a good example of lowmass-ion profiling in the setting of disease-screening using urine samples. This technique can be a powerful, non-invasive diagnostic tool with high sensitivity and specificity for NHL screening. Furthermore, hypoxanthine identified in this study may be a useful single urine marker for NHL screening. However, the biochemical mechanism responsible for the decreased levels of hypoxanthine and xanthine in urine samples from NHL patients remains to be elucidated.

\section{Acknowledgements}

This work was financially supported by research grants from the National Cancer Center, Republic of Korea (HSE; 0810440 \& BCY; 1010050), the Innovative Research Institute for Cell Therapy, Republic of Korea (HSE; A062260), and the Ministry of Knowledge, Economy \& Industrial Technology Development, Republic of Korea (BCY; 10032113).

\section{Author details}

${ }^{1}$ Colorectal Cancer Branch, Division of Translational and Clinical Research I, Research Institute, National Cancer Center, Goyang-si, Republic of Korea. ${ }^{2}$ Hematologic Malignancies Branch, Division of Translational and Clinical Research II, Goyang-si, Republic of Korea. ${ }^{3}$ Cancer Biostatistics Branch, Division of Epidemiology \& Management, Research Institute, National Cancer Center, Goyang-si, Republic of Korea. ${ }^{4}$ Hematology-Oncology Clinic, Center for Specific Organs Cancer, National Cancer Center, Goyang-si, Republic of Korea.

\section{Authors' contributions}

$\mathrm{BCY}$ and HSE conceived of the study, and participated in its design, coordination and data interpretation. SYK, WSP, TY and HSE performed pathological studies. SYK and SP carried out statistical analyses. SGJ, KHK and SAA carried out the mass analyses and metabolite identification. BCY drafted the manuscript. SP, WSP and TY advised on manuscript content and in critical revisions. BCY and HSE jointly wrote the final versions of the manuscript. All authors read and approved the final manuscript.

\section{Competing interests}

The authors declare that they have no competing interests.

Received: 25 May 2009

Accepted: 23 February 2010 Published: 23 February 2010

\section{References}

1. Alexander DD, Mink PJ, Adami HO, Chang ET, Cole P, Mandel JS, Trichopoulos D: The non-Hodgkin lymphomas: a review of the epidemiologic literature. Int J Cancer 2007, 120(Suppl 12):1-39.

2. Morrison VA: Non-Hodgkin's lymphoma in the elderly. Part 1: Overview and treatment of follicular lymphoma. Oncology (Williston Park) 2007, 21:1104-1110

3. Coiffier B: Treatment of non-Hodgkin's lymphoma: a look over the past decade. Clin Lymphoma Myeloma 2006, 7(Suppl 1):S7-13.

4. Nicolaides C, Fountzilas G, Zoumbos N, Skarlos D, Kosmidis P, Pectasides D, Karabelis A, Giannakakis T, Symeonidis A, Papadopoulos A, Antoniou F, Pavlidis N: Diffuse large cell lymphomas: identification of prognostic factors and validation of the International Non-Hodgkin's Lymphoma Prognostic Index. A Hellenic Cooperative Oncology Group Study. Oncology 1998, 55:405-415.

5. Ozgüroglu M, Turna H, Demir G, Döventas A, Demirelli F, Mandel NM, Büyükünal $E$, Serdengeçti $S$, Berkarda B: Usefulness of the epithelial tumor marker CA-125 in non-Hodgkin's lymphoma. Am J Clin Oncol 1999, 22:615-618.

6. Mihaljević B, Nedeljkov-Janćić R, Cemerikić-Martinović V, Babić D, Colović M: $\mathrm{Ki}-67$ proliferative marker in lymph node aspirates of patients with nonHodgkin's lymphoma. Med Oncol 2006, 23:83-89.
7. Lee HL, Eom HS, Yun T, Kim HJ, Park WS, Nam BH, Moon-Woo S, Lee DH, Kong SY: Serum and urine levels of interleukin- 8 in patients with nonHodgkin's lymphoma. Cytokine 2008, 43:71-75.

8. Vannoni D, Porcelli B, Caldarone R, Garzi A: Purine metabolism in human tumors. Medicina (Firenze) 1989, 9:51-54

9. Hashimoto H, Kubota M, Shimizu T, Kasai Y, Sano H, Adachi S, Akiyama Y, Mikawa $\mathrm{H}$ : Effect of high-dose methotrexate on plasma hypoxanthine and uridine levels in patients with acute leukemia or non-Hodgkin lymphoma in childhood. Leukemia 1992, 6:1199-1202.

10. Harkness RA: Hypoxanthine, xanthine and uridine in body fluids, indicators of ATP depletion. J Chromatogr 1988, 429:255-278.

11. Obajimi O, Melera PW: The depletion of cellular ATP by AG2034 mediates cell death or cytostasis in a hypoxanthine-dependent manner in human prostate cancer cells. Cancer Chemother Pharmacol 2008, 62:215-226.

12. Buhl L, Dragsholt C, Svendsen P, Hage E, Buhl MR: Urinary hypoxanthine and pseudouridine as indicators of tumor development in mesothelioma-transplanted nude mice. Cancer Res 1985, 45(3):1159-1162.

13. Linder N, Martelin E, Lundin M, Louhimo J, Nordling S, Haglund C, Lundin J: Xanthine oxidoreductase - clinical significance in colorectal cancer and in vitro expression of the protein in human colon cancer cells. Eur J Cancer 2009, 45:648-655.

14. Fini MA, Orchard-Webb D, Kosmider B, Amon JD, Kelland R, Shibao G, Wright RM: Migratory activity of human breast cancer cells is modulated by differential expression of xanthine oxidoreductase. J Cell Biochem 2008, 105:1008-1026.

15. Linder N, Lundin J, Isola J, Lundin M, Raivio KO, Joensuu H: Downregulated xanthine oxidoreductase is a feature of aggressive breast cancer. Clin Cancer Res 2005, 11:4372-4381.

\section{Pre-publication history}

The pre-publication history for this paper can be accessed here:http://www. biomedcentral.com/1471-2407/10/55/prepub

\section{doi:10.1186/1471-2407-10-55}

Cite this article as: Yoo et al:: Identification of hypoxanthine as a urine marker for non-Hodgkin lymphoma by low-mass-ion profiling. BMC Cancer 2010 10:55.

\section{Submit your next manuscript to BioMed Central and take full advantage of:}

- Convenient online submission

- Thorough peer review

- No space constraints or color figure charges

- Immediate publication on acceptance

- Inclusion in PubMed, CAS, Scopus and Google Scholar

- Research which is freely available for redistribution
C Biomed Central 